\title{
Auge y decadencia del puerto de Sevilla como cabecera de las
} rutas indianas

\author{
Pablo E. Pérez-Mallaína
}

\section{Resumen}

RESUMEN : En tanto puerto atlántico, Sevilla contó con las ventajas que le otorgaban la historia y la política, mientras que habían de serle fatales a mediano plazo los inconvenientes de la geografía. Una vida portuaria y urbana múltiple, hecha de esplendor y sinsabores. El río y sus trampas como componente ineludible del périplo indiano.

\section{Résumé}

RÉSUMÉ : Comme port atlantique, Seville était favorisée par l'histoire et la politique autant qu'elle était condamnée à moyen terme par les désavantages de a géographie. Une vie portuaire et urbaine multiple, faite de splendeurs et de désagréments. Le fleuve et ses pièges comme composante inéluctable du voyage américain.

\section{Citer ce document / Cite this document :}

Pérez-Mallaína Pablo E. Auge y decadencia del puerto de Sevilla como cabecera de las rutas indianas. In: Caravelle, $\mathrm{n}^{\circ} 69$, 1997. Ports d'Amérique latine. pp. 15-39;

doi : https://doi.org/10.3406/carav.1997.2753

https://www.persee.fr/doc/carav_1147-6753_1997_num_69_1_2753

Fichier pdf généré le 13/05/2018 


\title{
Auge y decadencia del puerto de Sevilla como cabecera de las rutas indianas
}

PAR

\author{
Pablo E. PÉREZ-MALLAÍNA
}

Universidad de Sevilla

\section{Una cuestión delicada: la elección de Sevilla como puerto y puerta de las Indias}

Se admite comúnmente que la elección de Sevilla para ser la sede de la Casa de la Contratación (ordenanzas de Alcalá de Henares de 20 de enero de 1503) significó el espaldarazo definitivo para que esta ciudad se convirtiese en la cabeza indiscutible de la administración del imperio ultramarino de Castilla. A la hora de explicar las razones que influyeron en esta decisión, cualquiera que conozca mínimamente la geografía de la Península Ibérica, no dudaría en incluir entre los argumentos a favor de tal elección la existencia del puerto fluvial sevillano sobre un río al que los árabes habían llamado "el grande". El Guadalquivir era, y sigue siendo, la corriente de agua más importante de Andalucía, aunque, en realidad, comparándolo con los grandes ríos mundiales o europeos, no pasa de ocupar un discreto lugar, no siendo, ni siquiera, el más caudaloso de los ríos españoles. Por todo ello podría decirse, a pesar de que la afirmación puede ser contraria a los tópicos más comunes, que a fines del siglo XV y principios del XVI, la calidad de su puerto era el más débil de 
los valores que la ciudad de Sevilla podía aportar frente a otras posibles candidaturas para ser la sede de la Casa de la Contratación.

Ahora bien, lo dicho hasta ahora no significa que la elección realizada en favor de Sevilla en 1503 fuese descabellada; por el contrario era muy razonable. Simplemente debe matizarse que, desde el punto de vista puramente técnico-náutico, resultaba discutible. Sevilla, desde hacía muchos ańos y antes de que a nadie se le ocurriese llegar a las Indias navegando hacia el oeste, se había convertido en la metrópoli de la Andalucía cristiana y en un centro demográfico, comercial, financiero, y administrativo de primer orden. Tanto era así que, en la mayoría de estos aspectos, resultaba difícil encontrar en Castilla una ciudad que la superase. Una parte de este éxito lo debía, sin duda, a su condición de puerto fluvial que la conectaba con el mundo conocido. Sin embargo, el tremendo desarrollo del comercio marítimo producido en la Europa Occidental entre los siglos XIII al XV, y del que Sevilla se había beneficiado, tenía dentro de sí la semilla que acabaría por provocar la decadencia del puerto sobre el Guadalquivir: el afán por abaratar los costes del transporte marítimo propició el constante aumento del tonelaje de las embarcaciones y, ya a finales del siglo XV, las grandes carracas de las repúblicas italianas que, a veces llegaban a las 1.000 toneladas de arqueo, no podían sońar con remontar la peligrosa barra de la desembocadura del Guadalquivir, ni enfrentarse con los cambiantes y traicioneros bajos de arena que entorpecían su curso. Por ello, a fines del siglo XV, Sevilla parecía tener los días contados como puerto de recalada del gran comercio transoceánico.

Es cierto que en 1503 los problemas del tránsito de las embarcaciones por el Guadalquivir aún no habían alcanzado límites dramáticos, pues existía una mayoría de buques con arqueos cercanos al centenar de toneladas y aun menores. Para los barcos de mayor tonelaje siempre se podía acudir, como se venía haciendo desde mucho tiempo atrás, a descargarlos y transportar sus mercancías en barcazas a través del río. Sin embargo, era una realidad que el tiempo jugaba en contra del puerto fluvial sevillano. Con todo, hay "decadencias" que, como las del imperio romano, pueden durar siglos, y en el caso de Sevilla las considerables ventajas de otro tipo que tenía la ciudad compensaron, por el momento, las deficiencias de su puerto fluvial, el cual, a pesar de los pesares, vivió a lo largo del siglo XVI el momento cumbre de su historia. Pero, ¿cuáles eran exactamente las razones que convencieron a los Reyes Católicos para 
decidirse por Sevilla como centro neurálgico del comercio transatlántico de su monarquía?

En primer lugar la ciudad constituyó desde su reconquista a los musulmanes un centro del poder real frente a una Andalucía que cayó progresivamente en manos de los grandes señores castellanos. La crisis de autoridad de los monarcas durante los siglos XIV y XV y la necesidad de contar con los recursos nobiliarios para sostener la peligrosa frontera con el reino nazarita de Granada, hicieron que una buena parte de la Andalucía cristiana, incluyendo sus mejores puertos, se convirtiesen en patrimonio señorial. Esto ocurrió con los puertos de la costa onubense tales como Ayamonte, Lepe, Cartaya, Huelva, Palos, o los del litoral gaditano como Sanlúcar de Barrameda, Chipiona, Rota, El Puerto de Santa María, Chiclana, Vejer, Cónil, etc. Los grandes magnates andaluces tales como los Guzmán (duques de Medinasidonia), los de la Cerda (condes y luego duques de Medinaceli) y los Ponce de León (marqueses de Cádiz), eran los propietarios de la práctica totalidad del litoral.

Sevilla, por el contrario, fue un bastión del rey frente al asalto de las jurisdicciones señoriales. Esa condición se veía reflejada físicamente por haberse convertido en lugar de residencia, tanto en vida como después de la muerte, para varios reyes de Castilla. La catedral se usó como tumba regia para Fernando III y Alfonso X y el antiguo alcázar musulmán se transformó en palacio regio, ampliado por Alfonso $\mathrm{X}$ y luego remodelado totalmente por Pedro I. Así pues, en esta ciudad se coronaron, enterraron o residieron de una forma casi permanente varios monarcas. Por ello, los Reyes Católicos, que hubieron de mantener una dura lucha por recuperar las parcelas de autoridad cedidas a la nobleza, era natural que eligiesen para ser cabecera de las nuevas rutas transoceánicas uno de los pocos puertos de realengo existentes en Andalucía.

En 1483, doña Isabel y don Fernando ya se habían visto obligados a fundar en la bahía de Cádiz un puerto que estuviese directamente bajo la autoridad de la Corona y que por ello recibió el expresivo nombre de Puerto Real. Más adelante, cuando Colón partió en su primer viaje hacia las Indias, los reyes compraron una parte del puerto de Palos para que la expedición no saliese de un lugar colocado bajo la exclusiva jurisdicción señorial. A la vuelta de la expedición colombina, las insinuaciones de algunos nobles de querer participar en los beneficios de la ruta recién abierta debieron ser escuchadas con preocupación por los monarcas, especialmente las formuladas por el duque de Medinaceli, que había sido 
uno de los valedores iniciales de Cristóbal Colón y que luego pretendía cobrarse tal ayuda ${ }^{1}$. Don Luis de la Cerda, duque de Medinaceli, era, además, señor del Puerto de Santa María, la localidad más populosa del litoral atlántico andaluz y un rival a tener en cuenta para el puerto sevillano. Sin embargo, las ventajas de un puerto de realengo como Sevilla eran a todas luces evidentes para una empresa que, tras la eliminación política de Colón a partir de 1500 , pretendía tener una dirección exclusivamente estatal.

Sevilla era una ciudad donde la autoridad del rey podía ejercerse sin las cortapisas del régimen señorial; en ella existía una burocracia de notable importancia $y$, además, desde su reconquista fue elegida por Fernando III como sede y origen de la naciente marina real castellana. Cuando en 1248 la ciudad fue tomada a los musulmanes, los castellanos dispusieron de un puerto desde el que lanzarse a aventuras ultramarinas, aun antes de haber dominado por completo el litoral atlántico andaluz. Ello debió encender la imaginación conquistadora de Fernando III y de su hijo Alfonso X. Por eso, una serie de medidas tomadas entre 1251 y 1254 convirtieron a Sevilla en la principal base de la marina real. Entre ellas, la primera consistió en conceder en 1251 un fuero al barrio marinero de la ciudad, que se denominaría Barrio de la Mar. Al año siguiente comenzaron los trabajos para reconstruir, poner a punto $y$ ampliar el viejo edificio de las atarazanas almohades, y en 1253 se contrató a una veintena de "comitres", esto es, capitanes de mar y guerra que debían sostener a medias con el rey otras tantas galeras. Finalmente, en 1254 se estableció en la ciudad un Almirantazgo, encargado de dirigir las actividades náuticas de la Corona ${ }^{2}$.

A través de estas medidas los monarcas castellanos conseguían tener concentrado en un barrio sevillano el elemento humano capaz de construir y tripular las embarcaciones, facilitándoles la organización de futuras expediciones marítimas, tanto mercantiles como militares. La vía central de dicho barrio tuvo durante siglos el expresivo nombre de "calle

\footnotetext{
1 A este aspecto existe una interesante carta del duque de Medinaceli dirigida al cardenal don Pedro González de Mendoza, fechada en Cogolludo a 19/III/1493. Véase: Gil, Juan y Consuelo Varela. Cartas de particulares a Colón y relaciones coetáneas. Madrid, 1984

2 Ortiz de Zúñiga, Diego. Anales eclesiásticos y seculares de la muy noble y muy leal ciudad de Sevilla. Sevilla, 1988, tomo I, págs. 64-65. También: Pérez-Embid, Florentino. "El almirantazgo de Castilla hasta las capitulaciones de Santa Fe". Anuario de Estudios Americanos. Tomo I, Sevilla, 1944. Del mismo autor: Estudios de Historia maritima. Sevilla, 1979.
} 
de la mar" (el cual le fue cambiado en fechas relativamente recientes por el menos expresivo de calle García de Vinuesa), y enlazaba la catedral, y su famosas gradas, con la puerta del Arenal que daba directamente al puerto fluvial sobre el Guadalquivir. Esta "collación" sevillana fue dotada de sus alcaldes, fueros y privilegios, con lo que se pretendía fomentar las vocaciones marineras para constituir el embrión de la marina real. La ampliación de las atarazanas almohades proporcionaría el astillero para las galeras y llegaría a ser, tras la catedral y el alcázar, el edificio de mayor planta de la Sevilla medieval. El contrato con los "comitres" pretendía solucionar la dirección militar $y$, por lo menos en parte, el mantenimiento de las embarcaciones. La instauración del almirantazgo, con el nombramiento en 1254 de don Ruy López de Mendoza como primer almirante, instauraba una dirección única para los asuntos náuticos, concentrando en esta figura el triple carácter de intendente y organizador de las expediciones, caudillo supremo y juez privativo en asuntos marítimos, con competencias civiles, criminales y comerciales.

Hasta entonces, Castilla tenía las bases de su poder naval en los puertos de la cornisa cantábrica. Pero este poder estaba en manos de los concejos municipales de las villas cántabras y vascongadas, dotadas de una gran autonomía gracias a sus fueros y privilegios. La marina de las villas del Cantábrico constituía una potencia naval considerable, pero se encontraba en manos de particulares y así siguió siendo durante muchos siglos. Lo que Fernando III y Alfonso $\mathrm{X}$ intentaron tras la conquista del reino de Sevilla era algo muy distinto: la instauración en la capital andaluza de los fundamentos de una marina de guerra que fuese propiedad directa de la Corona. Esa tradición y las instalaciones e instituciones con las que se dotó la ciudad desde finales del siglo XIII, también pesaron en la elección que se hizo en 1503.

Pero Sevilla no sólo era la fortaleza del poder real en Castilla, sino que también, tal y como la definió Ramón Carande, era un mercado. La ciudad, ya en la época musulmana y tras la decadencia de Córdoba como capital del califato andaluz, se fue convirtiendo poco a poco en la cabecera económica del valle del Guadalquivir, el cual suponía una vía de comunicación natural para una de las más prósperas regiones del occidente europeo, tanto por su riqueza agrícola como por sus abundadntes núcleos de población. Ya en el siglo XII, Sevilla había sido la capital europea del imperio almohade y desde su reconquista a mediados del siglo siguiente, fue la metrópoli económica de la Andalucía cristiana. El propio rey Alfonso X en su Crónica Genteral de España 
afirmaba que Sevilla mantenía durante el siglo XIII contactos comerciales con Tanger, Ceuta, Túnez, Bugía, Alejandría, Génova, Pisa, Sicilia, Lombardía, Cataluña, Portugal, Gascuña, Burdeos, y varios puertos de la costa de Inglaterra. Con todo, fue durante el siglo XV cuando se potenció extraordinariamente el papel comercial de toda Andalucía en general, y de Sevilla en especial. En ello tuvieron que ver dos factores importantes: en primer lugar la posición geográfica de la región, que la convertía cada vez más en un lugar de tránsito comercial y, en segundo lugar, la propia importancia de los productos autóctonos en los mercados internacionales.

El siglo XV va a ver florecer una ruta iniciada a finales del siglo XIII y que llevó a las repúblicas italianas a comerciar por vía marítima con Inglaterra y Flandes. La apertura del estrecho de Gibraltar a la navegación cristiana supuso un hecho decisivo en la economía de Occidente, pues puso en relación a los dos centros industriales más pujantes de la época: el norte de Italia y Flandes. La lenta ruta terrestre que los unía anteriormente atravesando los Alpes, se vio claramente superada por este nuevo camino marítimo y los intercambios se multiplicaron por cuarenta en pocos años ${ }^{3}$. Andalucía ocupaba en esta ruta un papel de intermediario y los navíos genoveses y venecianos, si bien no subían hasta Sevilla, solían hacer escala en Cádiz o Sanlúcar y, desde allí, las mercancías se transportaban en barcos más pequeños remontando el Guadalquivir.

Al mismo tiempo, el siglo XV verá la consolidación de las comunicaciones con los archipiélagos atlánticos y del lento recorrido de la costa africana, poniendo en relación los mercados andaluces con las producciones del Magreb y con las del Africa subsahariana. En este último caso, también la posición de la región andaluza era clave.

En resumen, Andalucía, y Sevilla como su capital, se veían colocados en el cruce de dos rutas comerciales básicas que unían el Este con el Oeste y el Sur con el Norte. Si se trazase una gran cruz latina que tuviese la base de su eje vertical en las repúblicas italianas y los dos extremos de su travesaño en Inglaterra y el Golfo de Guinea, el enlace se efectuaría necesariamente en la región que va desde Lisboa al estrecho de Gibraltar, y en este espacio, tras la capital portuguesa, Sevilla se mostraba como el principal centro urbano de la época. Por ello en la capital andaluza se

${ }^{3}$ Chaunu, Pierre. La expansion europea, siglos XIII al XV. Barcelona, 1972, págs. 37-38. 
podía encontrar el oro del Sudán, el azúcar de Canarias o los colorantes del Magreb, y junto a ello las ricas telas de Flandes, las armas italianas, el estaño inglés y las salazones del Mar del Norte. A todo ello, Andalucía añadía sus productos y los venidos de la meseta: trigo, aceite, vino, lana, cueros, frutos secos, y el mercurio de Almadén, que ya se usaba para extraer la plata por el procedimiento de amalgama ${ }^{4}$.

Este auge comercial atrajo rápidamente a un buen número de mercaderes y banqueros extranjeros, en cuyas manos estaba la comercialización y, en gran medida, el transporte marítimo. La propia geografía urbana de Sevilla conserva, en la denominación de sus calles, nombres que recuerdan la existencia de colonias de negociantes foráneos. Así las actuales calles "Alemanes" y "Francos", nos hablan de la componente septentrional y atlántica; mientras que las de "Placentines" (por los residentes de "Plasencia" o "Piacenza") o "Génova" (actualmente "Avenida de la Constitución"), son el testimonio de la presencia mediterránea. Entre todos los extranjeros, los genoveses fueron los más numerosos y activos 5 ; poco tiempo después de la reconquista de la ciudad, ya tenían su propio barrio y habían logrado del rey privilegios para asegurar sus posesiones y sus negocios, lo que propició que algunas de las principales casas bancarias genovesas se instalaran en Sevilla, haciendo que en ella fueran corrientes apellidos como Spínola, Grimaldi o Centurión. En suma, a finales del siglo XV, Sevilla era un importante centro financiero y comercial, lo que la convertía en un lugar muy adecuado para situar la base del naciente comercio transoceánico hacia las Indias occidentales.

La prosperidad económica fue acompañada por un notable aumento demográfico, con lo que Sevilla pudo convertirse a fines del siglo XV en la ciudad más poblada de Castilla, calculándose entre 40.000 y 65.000 el número de sus habitantes ${ }^{6}$. Si se compara esta población con la que

4 Pérez-Embid, Florentino. "Navegación y comercio en el puerto de Sevilla en la Baja Edad Media". En: Estudios de Historia marítima. Sevilla, 1979, págs. 123-176.

5 Heers, Jacques. Gênes au XVe. siecle. Activité économique et problèmes sociaux. Paris, 1961.

6 Domínguez Ortiz, A. "La población de Sevilla en la Baja Edad Media y en tiempos modernos". En: Boletin de la Real Sociedad Geografica. Madrid LXXVII, 1941, págs. 586608. Pérez Embid, F. "Navegación y comercio...", pág. 133. Ladero Quesada, M.A. Historia de Sevilla. La ciudad medieval Sevilla, 1980, pág. 73. Collantes de Terán, A. Sevilla en la Baja Edad Media. La ciudad y sus hombres. Sevilla, 1977. 
tenían por entonces los más importantes puertos andaluces de la fachada atlántica, la diferencia a favor de Sevilla es muy notable. El Puerto de Santa María tendría entre 6.000 y 6.500 habitantes. Huelva, Ayamonte y Sanlúcar de Barrameda rondarían los 4.500 habitantes. Palos tendría entre 3.000 y 3.500; mientras que Cádiz, Rota, Lepe o Cartaya no pasarían de los 2.0007. Esta circunstancia, como puede perfectamente comprenderse, proporcionaba a Sevilla una gran ventaja a la hora de reunir los hombres necesarios para las expediciones ultramarinas.

Finalmente, la situación del puerto sevillano, a casi 100 kilómetros tierra adentro, constituía un elemento de defensa contra dos de las amenazas más temidas por la Corona: los ataques de fuerzas navales enemigas y el contrabando. Contra la primera de dichas amenazas, la historia terminaría demostrando que fue muy acertada la decisión de colocar en Sevilla la cabecera de las rutas indianas, pues frente a los graves asaltos y saqueos que sufrieron Cádiz o el Puerto de Santa María a lo largo de los siglos XVI y XVII, Sevilla se vio totalmente a salvo de tales problemas, liberando, además, a la Real Hacienda de las costosas obras de fortificación que fue preciso realizar, por ejemplo, en la bahía gaditana. Sin embargo, con el contrabando ocurrió algo muy distinto y aunque era lógico pensar que los defraudadores tendrían más facilidades en los espacios abiertos de la bahía de Cádiz que en las más estrechas y vigilables orillas del Guadalquivir, lo cierto es que el afán de lucro puso en movimiento el ingenio humano y superó todas las dificultades. Asi pues, la condición de puerto fluvial de Sevilla no evitó que muchos millones de piezas de plata pasasen por delante de las autoridades fiscales sin pagar ningún impuesto.

En resumen, las ventajas que presentaba Sevilla eran muchas y evidentes. Su principal inconveniente se centraba en la dificultad del Guadalquivir para permitir el paso de grandes mercantes, tanto por la barra de Sanlúcar, en la desembocadura, como los cambiantes bajos de arena, aguas arriba. Las condiciones de navegabilidad fueron, además, empeorando a medida que el tráfico se volvía más intenso. Los accidentes y abordajes fueron frecuentes y el lecho del río fue quedando literalmente sembrado de cascos de navíos hundidos, los cuales suponían nuevos obstáculos añadidos a los muchos que ya tenía de manera natural. Cuando tratemos de la navegación entre Sevilla y Sanlúcar, volveremos a

7 Ladero Quesada, M.A. Historia de Sevilla... pág. 73. 
retomar este tema y será entonces el momento de profundizar en los inconvenientes del Guadalquivir como vía de comunicación comercial.

\section{Un puerto cosmopolita para una ciudad abierta: descripción del puerto y sus gentes}

A partir del descubrimiento de América, Sevilla se convirtió en una de las ciudades más populosas y cosmopolitas de Europa y, seguramente por eso, fue capaz de hechizar a un buen número de artistas y escritores que situaron en ella alguno de los mitos más conocidos de la literatura universal, dejándonos, de paso, imágenes más o menos fantásticas de la ciudad. Existen también descripciones más detalladas y cercanas a la realidad y al rigor que precisa la historia. Estas serían las proporcionadas por viajeros y cronistas locales, como por ejemplo, y sin salir del siglo XVI, las de Andrés Navagero, Jerónimo Munzer, Pedro de Medina, Alonso de Morgado, o Juan de Mal-Lara ${ }^{8}$. Junto con ello, poseemos una abundántisima colección de fuentes gráficas, pues a muchos artistas plásticos también les impresionó el colorido de la ciudad. En ese sentido, Sevilla aparecerá en diferentes tomos del Civitates Orbis Terrarum, el primer atlas moderno que recogía las vistas panorámicas de las más importantes ciudades del mundo y que, como es sabido, consta de seis tomos publicados entre 1572 y 1617 . Dibujantes, grabadores y editores como Joris Hoefnagel, Anton Van Wyngaerde, Ambrosio Brambilla o Joannes Janssonius, la representaron o editaron libros en las que la ciudad se describía con abundante lujo de detalles; lo mismo hicieron pintores famosos como Francisco Pacheco, o artistas anónimos, como el llamado "maestro de Moguer", que en el cuadro que se conserva en la Iglesia de Santa Ana, nos ha legado la representación pictórica más antigua de Sevilla, sin olvidar a los autores de las vistas del puerto y de los trabajos en las orillas del Guadalquivir que se conservan en la Hispanic Society de Nueva York y, sobre todo, la espléndida visión de la ciudad y su puerto que muestra a la Sevilla de los últimos años del siglo XVI y es una de las joyas del Museo de América de Madrid?. Con todo ello y a

8 Sobre las fuentes para el conocimiento de la Sevilla del siglo XVI puede consultarse la bibliograffa recogida por Francisco Morales Padrón en su obra: Historia de Sevilla. La ciudad del Quinientos. Sevilla, 1977.

9 Todas estas representaciones gráficas han sido recopiladas y estudiadas por $\mathrm{M}^{\mathbf{a}}$ Dolores Cabra Loredo y Elena Ma Santiago Páez, en la obra: Iconografia de Sevilla, 1400-1659. Sevilla, 1988. 
pesar del tiempo transcurrido, no es del todo difícil darse un paseo imaginario por el puerto de Sevilla en los momentos de su mayor esplendor, allá por el final del siglo XVI.

En aquellas fechas se registra el momento álgido del tráfico marítimo con las Indias y todo el Guadalquivir, desde Sanlúcar de Barrameda hasta la propia capital hispalense, se convirtió en un puerto de casi cien kilómetros de longitud, en el que anclaban centenares de navíos. Los más pesados y voluminosos no podían remontarlo y solían quedar a medio camino, mientras que los más ligeros llegaban hasta la propia Sevilla. En ella, el corazón del puerto se encontraba en los 650 metros que separaban la almohade Torre del Oro del puente de barcas que unía Sevilla con el arrabal de Triana, situado en el mismo lugar que hoy ocupa el más antiguo de los puentes de la ciudad, construido en el siglo XIX en tiempos de la reina Isabel II. En esta zona las dos orillas del río proporcionaban un kilómetro y medio de varaderos fangosos, donde se apiñaban un enjambre de embarcaciones, las cuales se encallaban de manera perpendicular a la orilla para poder aprovechar mejor el espacio. En la margen derecha, ocupada por el barrio de Triana, las casas llegaban casi al límite del agua ; sin embargo, en la izquierda, las murallas de la ciudad distaban entre 200 y 300 metros de la orilla. Esta explanada, cubierta por los sedimentos del río, era el famoso Arenal, el cual, hoy en día, sigue dando nombre a uno de los barrios más típicos de la ciudad. El agitado trajín de este singular espacio urbano ya fue recreado por Lope de Vega en su comedia El Arenal de Sevilla, de donde proceden estos conocidos versos:

\section{Famoso está el Arenal \\ ¿Cuándo lo dejó de ser? \\ No tiene a mi parecer \\ todo el mundo vista igual}

La panorámica que presentaba la ciudad desde Triana debía constituir una visión realmente extraordinaria. Ahora bien, si el poeta daba la visión hermoseada por la literatura, un visitante menos condescendiente con las musas podría observar además del bullicio de los paseantes y el colorido de los tenderetes, no pequeñas cantidades de desperdicios que, arrojados en montones, llegaban a constituir auténticas colinas artificiales (los tristemente famosos "muladares") y, posiblemente, sentiría la incomodidad de embarrarse el calzado y la ropa con las lluvias del otoño o de sofocarse con la polvareda y el calor del verano. Pero dejemos los 
detalles para más adelante y comencemos la descripción del puerto sevillano en su época de esplendor.

Mirando desde Triana, a la izquierda aparecía el puente de barcas que delimitaba uno de los extremos del puerto, pues al otro lado, aguas arriba, sólo navegaban pequeñas barcas de pesca o de transporte de pasajeros. Este puente, tendido entre el castillo de la Inquisición en el Altozano trianero y la Puerta de Triana de la muralla de Sevilla, era el único enlace fijo que unía las dos orillas del río y así siguió ocurriendo hasta la construcción del primer puente fijo en tiempos de Isabel II ya en pleno siglo XIX.

La primera noticia del puente de barcas data del tiempo del califa almohade Abu Yaqub Yusuf, que debió construirlo en el último tercio del siglo XII. A comienzos del siglo XVI su conservación estaba entregada por contrato a un particular, al cual solía denominarse "amo del puente" 10 . En realidad, el arrendador no era propietario de nada y tan sólo, a cambio del dinero que le entregaba el Cabildo municipal, se encargaba de mantenerlo en servicio, renovando periódicamente las barcazas de roble que los formaban. Estas eran trece, según confirma un magnífico dibujo de Anton van den Wyngaerde realizado a mediados del siglo XVI ${ }^{11}$. La anchura total era de unos diez metros, estando protegido el paso de las personas y las caballerías con una barandilla de madera. La conservación de esta fundamental vía de comunicación fue siempre un quebradero de cabeza para el Cabildo, pues las crecidas del río, los golpes que le proporcionaban las embarcaciones, o la simple desidia de los arrendadores lo solían mantener en un estado precario. Con todo, y aun en sus mejores momentos, resultaba insuficiente para una ciudad como la Sevilla de entonces: un informe de principios del XVI cifraba en 3.000


animales estaba regulado y limitado a pequeños grupos, para evitar el deterioro que podía producir el paso en tropel de los rebaños.

Cabe preguntarse por qué no se llegó a contruir un puente de piedra. La necesidad era evidente y como prueba baste con observar como en

10 Navarro García, Luis. "El puerto de Sevilla a fines del siglo XV". En: Archivo Hispalense, Sevilla, 1966, págs. 1-38.

11 Cabra Loredo, Ma Dolores y Elena M. Santiago Páez. Iconografia de Sevilla. Tomo primero. 1400-1650. Sevilla, 1988, págs. 76-77.

12 Ibidem., pág, 165. 
muchos documentos gráficos se detalla la gran cantidad de barcas que se dedicaban a cruzar pasajeros de una orilla a otra. Se ha querido indicar que la vieja aspiración de hacer navegable el río hasta Córdoba fue una de las razones principales que hizo escoger esta situación de tipo provisional $\mathrm{y}$, por tanto, mucho más fácil de eliminar cuando, por fin, se realizase el anhelado proyecto. Con todo, hay muchos informes contemporáneos que nos hablan de que la verdadera razón fue puramente técnica: problemas de cimentación por la blandura del fondo en ese tramo del río, exceso de caudal y profundidad fueron los factores que, al parecer, impusieron la solución más fácil y barata, al menos a corto plazo ${ }^{13}$.

La parte de la muralla de Sevilla que daba al puerto presentaba cuatro entradas que daban sobre el Arenal. De norte a sur la primera era la puerta de Triana, que en 1492 seguía siendo poco más que un pequeño postigo, pues no fue hasta la segunda mitad del XVI cuando se construyó una entrada de estilo renacentista y de mayor empaque. En segundo lugar y casi en el centro del lienzo de murallas, estaba la entrada principal de la ciudad en esta zona portuaria: la puerta del Arenal. A través de ella se pasaba a la llamada calle de la Mar, la cual constituyó el eje del barrio marinero fundado por Fernando III y que, en un recorrido de apenas cien metros, enlazaba el puerto con la Catedral, rodeada de tenderetes, oficinas de escribanos y de unas escalinatas (las "gradas"), lugar de cita y de negocios en el corazón de la ciudad. De esta manera y a través de la recta calle de la Mar, quedaban enlazados los dos polos de la vida comercial y marítima de Sevilla, esto es, el puerto y el principal centro urbano de contratación de hombres y mercancías. Andrés Navagero, el curioso embajador de Venecia describía así el ambiente de las gradas de la catedral en el primer tercio del siglo XVI:

"Alrededor de todo el edificio, asi de la iglesia como del claustro y delante de la fachada, hay un embaldosado de mármoles bastante ancho cerrado de cadenas, del cual se baja a la calle por varios escalones (no por todas partes, pues la fachada del Mediodia está al andar de la calle). A este lugar acuden a pasearse todo el dia muchos hidalgos y mercaderes y es el sitio más bello de Sevilla, que llaman las gradas. A la calle y plaza que está delante concurre

13 A los problemas técnicos como explicación de la inexistencia de un puente de piedra se refiere un informe dirigido por el Asistente de la Ciudad al Conde-Duque de Olivares en 1631. Ibidem., pág. 163-166. 
también de contínuo; allí se hacen muchos encantos y es como una especie de mercado"l4.

Pasada la puerta del Arenal sólo quedaban dos pequeños postigos: el del Aceite (que es. el único que hoy se conserva) y el del Carbón. Este era inmediato al paseo de ronda que, partiendo perpendicularmente de la muralla, llegaba hasta la misma orilla del río donde se levantaba la imponente torre del Oro. Pasada esta fortificación, la muralla hacía un ángulo de 90 grados y se alejaba del río siguiendo una dirección paralela a un pequeno afluente del Guadalquivir, el arroyo Tagarete, que desembocaba un poco más al sur de la Torre del Oro. Aquí terminaba la zona portuaria propiamente dicha de la ciudad, aunque las márgenes cercanas y su arrabal de Triana seguían usándose por muchas embarcaciones como careneros y fondeaderos ocasionales.

Ahora bien, las murallas de la ciudad construidas en el siglo XII significaban ya un cinturón demasiado estrecho y varios conjuntos de edificios se habían construido en el Arenal entre sus muros y la orilla del río. Dos de ellos constituían sendos arrabales, cuyo origen estaba en los almacenes de mercancías y en las viviendas de las personas cuyos oficios tenían que ver directamente con el tráfico fluvial y marítimo: guardas de almacenes, carreteros, costaleros, esportilleros, toneleros, así como de una serie de personajes marginales que siempre circulan alrededor de las zonas portuarias. Los dos barrios llevaban los expresivos nombres de la Cestería y la Carretería, el último de los cuales sigue ligado a la toponimia urbana y religiosa de la ciudad actual. Estaban colocados a ambos lados de la puerta del Arenal, de tal manera que esta entrada a la ciudad parecía colocada al extremo de una especie de estrecho pasillo que formaba el caserío de los arrabales.

El tercer conjunto de edificaciones que habían saltado la muralla eran las atarazanas. Se trataba de una fundación almohade, restaurada $y$ ampliada por Fernando III y Alfonso $\mathrm{X}^{15}$, que se apoyaban en los muros, entre el postigo del Aceite y el del Carbón. Su planta era un gran cuadrilátero de más de 180 metros de lado, dividido en 16 naves mediante pilares, los cuales sostenían una techumbre formada por

\footnotetext{
${ }^{14}$ Navagero, Andrés. Viaje por España. 1524-1526. Madrid, 1983, pág. 35.

15 Torres Balbás, L. "Atarazanas hispano-musulmanas". En: Al-Andalus, no 11, Madrid, 1946. Véase también: Pérez-Embid, Florentino. "La marina castellana en el siglo XIII". En: Estudios de Historia marítima. Sevilla, 1979, págs 71-127.
} 
bóvedas de medio cañón apuntado. El cuadro al óleo del llamado "maestro de Moguer", datado a finales del siglo XV y que se conserva en la iglesia de Santa Ana en Triana, constituye la más antigua ilustración de las atarazanas de Sevilla y muestra los amplios portalones del edificio abiertos sobre el arenal para facilitar así la entrada y salida de las embarcaciones. Con algo más de detalle se representan las atarazanas en un grabado que ilustraba la obra del cosmógrafo Pedro de Medina, Libro de las grandezas y cosas memorables de España, publicado por primera vez en 1548, así como en otro grabado de Ambrosio Brambila publicado en el tomo IV del Civitates Orbis Terrarum de 1585. Las imágenes posteriores del edificio señalan la construcción de una portada monumental, y con ella aparecen las Atarazanas en el cuadro anónimo del Museo de América de Madrid (fines del siglo XVI) o en el grabado editado por Janssonius en 1617.

Desde comienzos del siglo XVI, las atarazanas habían dejado de ser un lugar en el que se construían las galeras del rey y su función puramente marítima se circunscribía a ser un almacén de maderas, cañones, aparejos y demás pertrechos necesarios para armar los barcos de guerra que protegían las flotas y las rutas de las Indias; pero, además, este gran edificio tuvo otros muchos usos, ya que se utilizó como aduana, como cárcel e, incluso, pensó colocarse en él la primitiva Casa de la Contratación.

Nada más pasar las Atarazanas se abría el postigo del Carbón, también llamado de los Azacanes y del Oro, por las ingentes riquezas que pasaron bajo sus arcos. Al lado, como hemos dicho, se encontraba la torre del Oro, y justo delante de esta fortificación estaba la única grúa de que disponía el puerto sevillano. Esta máquina denominada en los textos con los apelativos de "el ingenio" o "el muelle", se había colocado a principios del siglo XV a expensas del Cabildo de la catedral con la idea de facilitar la descarga de las pesadas piedras destinadas a la terminación del templo mayor de la ciudad ${ }^{16}$. La imagen más antigua que poseemos de esta grúa nos la vuelve a proporcionar el lienzo de la Iglesia de Santa Ana, en el cual se destaca desproporcionadamente la mole del "ingenio", formado por una plataforma cilíndrica de piedra sobre la que se fijaba dos grandes ruedas colocadas en paralelo y unidas sus circunferencias por travesaños de madera. De ellas salía un largo brazo móvil del que pendía

16 Pérez-Embid, Florentino. "Navegación y comercio en el puerto de Sevilla en la Baja Edad Media". En: Estudios de Historia maritima. Sevilla, 1979, pág. 159. 
un gancho para levantar la carga. La fuerza impulsora de esta máquina era humana y en algún grabado posterior se puede apreciar la presencia de varias personas colocadas en el interior de las ruedas, que eran accionadas cuando los trabajadores comenzaban a subir por la escalera sin fin que formaban los travesaños que las unían.

Excepto la torrecilla de piedra que servía de plataforma al "ingenio", no existía en todo el puerto otra construcción de cal y canto que pueda parecerse a lo que hoy denominaríamos un muelle. Cuando los documentos señalan la existencia del "muelle" de Sevilla se refieren exclusivamente a la base de su única grúa. Así pues los buques que llegaban a la capital andaluza tenían que varar en las orillas de arena o permanecer abarloados en los fangosos fondeaderos del río. Es pues interesante preguntarse cuál era el nivel de equipamiento del puerto fluvial del Guadalquivir en relación con el resto de los puertos españoles y europeos. En la segunda mitad del XVI y dentro de España, las imágenes recogidas en la primera edición del Civitates orbis terrarum muestran que Sevilla estaba tan bien equipado como el mejor de los puertos del momento. Tan sólo en los de Málaga y Santander se aprecia una grúa semejante a la que existía al pie de la torre del Oro. La ciudad cántabra disponía además de sólidos muelles de piedra, lo que la convertía, quizá, en el puerto mejor dotado de España, pero en otros tan significativos como Barcelona, Bilbao, San Sebastián o Cádiz no puede apreciarse ni el más leve rasgo de obras de infraestructura. Ahora bien, la comparación con los grandes puertos europeos del momento es claramente desventajosa para Sevilla. Así en el último tercio del siglo XVI, Londres poseía siete u ocho grúas colocadas sobre muelles en forma de "u" a los cuales se acercaban las barcazas que realizaban la descarga de los grandes mercantes que permanecían fondeados en el Támesis. Amberes, uno de los puertos mejor equipados del momento, disponía de tres grúas y siete amplios muelles rectangulares, que sobresalían sobre el río Escalda, permitiendo con ello el atraque directo de grandes buques. En Colonia sólo aparecen atracadas barcazas de un solo mástil, pero dispone de media docena de grúas. En las representaciones de Lisboa o de Amsterdam sólo se aprecia una grúa en cada uno de estos puertos, colocadas en las cercanías de los lugares en los que se construían los navíos. En el caso del puerto lisboeta se representan cinco grandes muelles, posiblemente de madera, que se adentran perpendicularmente en el Tajo y donde atracaban embarcaciones menores y carabelas, mientras que los galconcs y carracas permanecían fondeados en el centro 
del río. Otros grandes puertos de la época como Venecia, Génova, Nápoles o Marsella no parecen poseer máquinas para facilitar la carga y descarga, pero están dotados de grandes muelles de piedra o de pantalanes de madera que permiten el acercamiento a la orilla de buques medianos y grandes.

Tampoco poseyó Sevilla ningún dique para realizar las carenas y reparaciones de los barcos. En 1533 se elevó a la Corona un memorial proponiendo construir un gran carenero a orillas del Guadalquivir, pero el proyecto quedó tan sólo en eso ${ }^{17}$. Por ello, cuando se necesitaba repararlos, los buques eran echados sobre sus costados sobre las orillas del río. En esta operación la estructura de la embarcación solía sufrir bastante y, además, el barro del río solía impedir que se descubriese la totalidad de la quilla. Los accidentes eran frecuentes y los cascos de los buques perdidos durante el proceso de reparación inutilizaban los careneros, que eran abandonados en busca de trozos de orillas libres. Hubo algunos procedimientos algo más sofisticados con los cuales no era necesario sacar el barco del agua; para ello se usaban grandes barriles vacíos que servían de flotadores e impedían que el barco se hundiese cuando se le acostaba sobre el agua, pero el sistema de realizar la carena en la orilla fue el más comúnmente utilizado.

La descripción de este ámbito portuario que constituía el Arenal Sevillano estaría incompleta sin referirse a las gentes que lo poblaban. En principio debe destacarse su condición de zoco o mercado. Desde las proximidades del puente de barcas hasta las atarazanas y delante de los arrabales de la Cestería y la Carretería se levantaba un amplio mercadillo, cuyos puestos se protegían del terrible sol sevillano por medio de toldos cónicos, especie de tiendas de campaña sobre trípodes. Este mercado tenía diferentes sectores según las mercancías expuestas a la venta. En las cercanías del puente se ofrecían ladrillos, cal, diversos pescados frescos y salados, melones y otras frutas; más allá, en las proximidades de la puerta del Arenal, se localizaban puestos con un sinnúmero de mercancías de poco precio y valor, es decir baratijas, que otorgaron su nombre a esta parte del puerto: el Baratillo, con el que aún se sigue conociendo la zona. En las cercanías de las Atarazanas y de la torre del Oro, el mercadillo era sustituido por una serie de grandes montones de troncos y tablones de madera, cañones apilados y conjuntos de barriles y aparejos que se

17 Navarro García, Luis. "El puerto de Sevilla...", págs. 27-28. 
sacaban de los buques de guerra. Allí también habían surgido, llegando casi hasta la orilla, almacenes para guardar este tipo de materiales. Ya en el río, y además de los barcos varados o fondeados, se encontraban los barqueros que transportaban a pasajeros de una a otra orilla en botes entoldados.

Curiosamente, ni en las ilustraciones, ni en los documentos, aparecen referencias de astilleros en el Guadalquivir. Tan sólo una pintura al óleo, que se conserva en la Hispanic Society de Nueva York, muestra trabajos de esta índole, pero en realidad se trata más bien de obras de reparación que de construcción. La desforestación de Andalucía y la mala calidad de las maderas de los pocos bosques que quedaban hizo que, desde mediados del siglo XVI, se prohibiese que buques construidos en esta región se incorporaran a las flotas de Indias. Algunas maderas llegaban a través del Guadalquivir desde la sierra de Segura, pero nunca con la abundancia y la calidad requeridas. Los buques oceánicos españoles no nacían en el sur, sino que se botaban en la cornisa cantábrica, cerca de los bosques de robles y de las acerías norteñas. Sevilla tampoco fue un puerto industrial y el tráfico con las Indias no repercutió en la aparición de grandes astilleros ni de sus manufacturas complementarias.

Lo que sí se podía encontrar en el Arenal, para desgracia de sus sufridos paseantes, eran los montones de basuras o "muladares", que formaban auténticas colinas artificiales, apreciables en la mayoría de las representaciones gráficas de la época. El Ayuntamiento llegó incluso a crear los desagradables oficios de "guardas de las inmundicias"; éstos debían impedir que los vecinos siguiesen con la antigua costumbre de desembarazarse de las basuras arrojándolas al otro lado de las murallas, pero a fines del siglo XVI se suprimieron tales cargos ante su demostrada ineficacia para eliminar esos insalubres hábitos ${ }^{18}$. Así pues, entre las basuras, las polvaredas del verano y los barros del invierno, el Arenal no debía ser un lugar limpio, como tampoco lo era cómodo, pues estaba cruzado por un buen número de pequeñas corrientes de agua, algunas de las cuales precisaban de puentecillos para ser franqueadas. Pero todas estas molestias no impedían que la zona se encontrase frecuentemente llena de curiosos que deseaban ver llegar las embarcaciones o, simplemente, para practicar la tan española costumbre de ver trabajar a los demás. Las ilustraciones y pinturas de la época muestran

18 Ibidem. Págs. 6 y 7. 
generalmente a un Arenal concurrido por los tipos más variados de gente; algunos van en procesión detrás de un santo, otros riñen a espada, las damas pasean acompañadas de sus criadas, y en todas direcciones atraviesan carrozas y recuas de mulas transportando la carga de los barcos.

Al otro lado del río, Triana fue inicialmente un barrio de alfareros, pescadores fluviales y hortelanos. En la primera mitad del siglo XVI apenas tenía más que dos o tres calles paralelas con grandes solares dedicados a huertas. Sin embargo, en poco tiempo, Triana se habría de convertir en la residencia por excelencia de la gente de mar de la Carrera de Indias. Allí, frente al río, construirían los marineros su hospital y la sede de su asociación gremial: la Universidad de Mareantes. De alguna forma este hecho suponía una alteración en los planes trazados por el rey Fernando III. Al reconquistar la ciudad, el monarca había decidido construir un barrio situado intramuros, muy cerca de la catedral, cuyos vecinos debían navegar con galeras el estrecho de Gibraltar y el Mediterráneo. Sin embargo, el corazón marítimo de la ciudad terminó siendo el arrabal de Triana, cuyos vecinos, con naos y galeones, habrían de surcar el mar océano.

\section{De Sevilla a Sanlúcar: la navegación por el Guadalquivir}

El puerto de las Muelas, como se denominaba el primitivo fondeadero de la Sevilla medieval, comprendido entre la Torre del Oro y el puente de barcas de Triana, se hizo muy pronto insuficiente para el gran número de embarcaciones que surcaron el Guadalquivir a partir de 1492. Primero se habilitaron como lugares de atraque las orillas cercanas a la ciudad y surgieron los muelles de San Telmo y Tablada; un poco más abajo, la localidad de San Juan de Aznalfarache se convirtió en el lugar más concurrido para aquellos buques que necesitaban realizar reparaciones de cierta envergadura (carenado). Pero las grandes embarcaciones que superaban las 500 toneladas rara vez pasaron más arriba del paraje denominado las Horcadas, a medio camino entre Sevilla y la desembocadura del río.

Ya se indicó al principio que el Guadalquivir, como vía de comunicación, tenía serios problemas para ser utilizado por embarcaciones de gran tonelaje. Los documentos de la época ponen claramente de manifiesto que en recorrer las quince o dieciséis leguas de 
curso fluvial ${ }^{19}$ se tardaba por lo menos siete días, es decir, ¡el mismo tiempo que empleaban las flotas para llegar desde Sanlúcar a las islas Canarias! La explicación de este hecho estaba en la existencia de una serie de bajos fondos a lo largo del recorrido, que obligaba a detenerse a las embarcaciones hasta poder contar con una serie de condiciones favorables necesarias para salvar el obstáculo. Dichas condiciones debían darse al mismo tiempo y en resumen eran: viento favorable; luz diurna para poder observar las marcas de profundidad instaladas en los pasos más difíciles; $y$, finalmente, marea con la dirección y el volumen de agua convenientes. Aun en el caso de que se dieran todos los requisitos favorables, algunas naves grandes debían ser alijadas parcialmente para pasar los bajos, y si el viento, la variable más aleatoria, no soplaba a favor, era preciso remolcar el buque con barcas de remo. Pero aun en el mejor de los casos, en atravesar cada una de las dificultades más importantes, y había seis o siete a lo largo del río, se solía perder un día entero ${ }^{20}$.

La formación de estos bajos de arena es un fenómeno muy normal en el curso bajo de un río de llanura, pero además, las violentas lluvias de la primavera y del otońo daban lugar a frecuentes desbordamientos; cuando las aguas volvían a su cauce, algunos bajos habían aumentado de espesor, otros habían variado ligeramente de posición e, incluso, podían aparecer algunos nuevos.

A las dificultades naturales se fueron añadiendo las provocadas por la mano del hombre. Desde antiguo existían a la salida del puerto de las Muelas los peligrosos pilares hundidos de un antiguo puente romano situado en las proximidades de San Juan de Aznalfarache; ésta era la zona que se denominaba "los pilares" y que el general de flotas Juan de Escalante califica como uno de los lugares más peligrosos del río ${ }^{21}$. Pero unos obstáculos mucho más numerosos los fueron formando las decenas de cascos de buques hundidos en accidentes o, simplemente, echados al través en las orillas por viejos o inservibles. Estos últimos si bien no

19 Juan López de Velasco en su Geografia y descripción universal de las Indias ( Madrid 1971, pág. 35) da una longitud de 15 leguas (una legua = 5,57 kms.) para la distancia entre Sevilla y Sanlúcar. Juan de Escalante de Mendoza en su Itinerario de Navegación (Madrid 1985, pág. 26) otorga a ese mismo recorrido una distancia de 16 leguas. En realidad resulta difícil precisar la longitud del curso del río en el siglo XVI, pues desde entonces ha sido alterado a través de canalizaciones que han recortado sus meandros.

20 López de Velasco, Juan. Geografla.... pág. 35.

21 Escalante de Mendoza, Juan. Itinerario de Navegación..., pág. 27. 
estorbaban la navegación, sí dificultaban las labores de atraque y carenado. Otro problema, mucho menos evidente, se sumó a los anteriores: en las proximidades de Sevilla, los talleres de alfarería existentes en la ciudad obtenían de las orillas del río la materia prima para confeccionar sus cacharros, lo cual, tras siglos continuados de extracciones, terminó por provocar el desmoronamiento de las márgenes del Guadalquivir, dificultando la aproximación de las embarcaciones a tierra. El Cabildo llegó a nombrar "guardas del barro" para evitar tales acciones, cuya eficacia fue parecida a sus colegas encargados de vigilar el vertido de inmundicias. Los alfareros se las ingeniaron para seguir sacando arcilla y, por otra parte, el Cabildo no podía realizar una política de estricto cumplimiento de las ordenanzas si no quería destinar a la ruina a una de las pocas industrias florecientes de la ciudad ${ }^{22}$.

Con todas estos inconvenientes, el río de Sevilla se fue convirtiendo en un auténtico cementerio de buques accidentados y cada nuevo naufragio aumentaba la peligrosidad de su cauce. Según los cálculos de Chaunu, entre 1504 y 1650, el 8\% de las pérdidas totales de navíos de la Carrera de Indias se produjeron en el Guadalquivir. Desde fines del siglo XVI y a todo lo largo del XVII, se hicieron proyectos para limpiar el río y llegaron a contratarse los servicios de ingenieros, normalmente extranjeros, que realizaron la extracción de algunos cascos hundidos, pero su labor fue absolutamente insuficiente ante el imparable progreso de los accidentes y del propio tamaño de las embarcaciones ${ }^{23}$.

Si la navegación a lo largo del Guadalquivir era peligrosa, atravesar la barra de Sanlúcar de Barrameda, en la misma desembocadura, significaba un temible principio o un fatal colofón para un viaje oceánico. Un informe realizado hace algunos años ha podido reseñar más de 160 naufragios en la barra de Sanlúcar a lo largo de los siglos XVI, XVII y $\mathrm{XVIII}{ }^{24}$, lo que supone unas pérdidas superiores a las acaecidas en el curso del río. La peligrosidad de la barra se debía, y aún se debe hoy en día, a una triple conjunción de factores: el fango transportado por el Guadalquivir; las toneladas de arena que la erosión de los acantilados

22 Navarro García, Luis. El puerto de Sevilla..., págs. 22-26.

23 Pérez-Mallaina Bueno, Pablo E. "Decadencia del puerto fluvial de Sevilla. Un "ingenio" para sacar navíos hundidos en el siglo XVII". En: Revista General de Marina. Madrid, enero, 1977, págs. 33-40.

24 Lakey, Denise C. Shipwrecks in the Gulf of Cadiz. Original mecanografiado que se conserva en la biblioteca del Archivo General de Indias de Sevilla, mayo de 1987. 
cercanos deposita en la desembocadura; y, finalmente, la existencia de bajos fondos de roca. Este tapón de fango, arena y rocas, que ha sido comparado a la trombosis que estrangula una arteria, era tan peligroso para la vida humana como esta enfermedad y, también como ella, segó miles de vidas humanas ${ }^{25}$.

Por otro lado, cuando la avaricia, los errores humanos o los excesos de la burocracia se unían a los peligros naturales, los desastres marítimos se incrementaban. De esta manera, muchos naufragios fueron propiciados por intentar ahorrarse el dinero que costaba alijar las embarcaciones o, simplemente, por sobrecargarlas. Otra causa muy frecuente fue el descuido y la incompetencia de los pilotos prácticos de la barra o del río. Finalmente, el temor de los oficiales del rey a que se realizase contrabando hizo que se mantuviese alejadas de barcos en apuros a las embarcaciones menores que podían haberlos auxiliado ${ }^{26}$.

Conocidos los peligros del río, puede ser interesante para concluir este trabajo describir como vivían los hombres del siglo XVI una navegación por el Guadalquivir y para ello podemos valernos de las precisiones de un geógrafo cómo Juan López de Velasco y las curiosísimas anécdotas de un marino que navegó muchas veces por el río: el general de flotas, Juan de Escalante 27 .

Lo primero que llama la atención era que una gran parte de las mercancías y de los pasajeros no hacían el trayecto hasta Sanlúcar dentro de las embarcaciones en las que luego cruzarían el Atlántico, sino que debían contratar barcas a remo y vela, las cuales, por su menor calado, podían salvar mejor los bajos del Guadalquivir. Había una reglamentación muy antigua de este tráfico y existía la figura del "alcalde del río", que a fines del siglo XVI era elegido en votación secreta por el cabildo municipal y se encargaba de dirimir los pleitos entre los barqueros ${ }^{28}$. Estos llegaban a acuerdos para regular y repartirse el negocio entre todos y excluir a posibles nuevos candidatos que llegaran con

25 Vanney, Jean-René y Loïc Menanteau. "La barra de Sanlúcar". En: El río. El bajo Guadalquivir. Madrid, 1985.

26 Ese fue, precisamente, el caso de uno de los naufragios más famosos ocurrido en la desembocadura del río: el de la capitana de Nueva España de 1641. Archivo General de Indias, Contratación 179.

27 López de Velasco, Juan. Geografia... y Escalante de Mendoza, Juan. Itinerario de navegacion...

28 Navarro García, Luis. "El puerto de Sevilla...", pág. 9-11. 
intención de participar en aquel lucrativo tráfico, para lo cual habían formado un auténtico monopolio de carácter gremial. El propio nombre que se daba a las embarcaciones que hacían el recorrido del Guadalquivir, "barcos de la vez", nos está hablando de la existencia de una rigurosa ordenación del negocio ${ }^{29}$. Cómo comentaba Escalante,

"...los barcos que asi tiene este oficio se llaman "de la vez" y ninguno puede llevar o traer gente de esta suerte sino ellos, que tienen y han de tener cierto tamaño...y que allá tienen sus antiguas ordenanzas y alcalde... "30.

La picaresca hacía que también estos "barcos de la vez" fuesen cargados en demasía, mientras que la pereza de los marineros imponía la navegación a vela para no tener que remar. Ya en los tratados árabes sobre la navegación por el Guadalquivir se hace referencia a la natural repugnancia que los marineros de los barcos fluviales tenían a empuñar los remos, y, de este modo, en el tratado de Ibn Abdún se recuerda a los pasajeros que no tienen obligación de atender la sugerencia de los patrones de que ayuden en la boga "...porque son ellos quienes han de contratar las gentes que carguen y hagan avanzar el barco, ya que el barco es como una caballería de alquiler, a cuyo propietario le incumbe dirigirla y alimentarla"31. Juan de Escalante, por su parte, ponía en guardia frente al tremendo peligro que suponía navegar con viento contrario en aquellos barquichuelos sobrecargados, pues en cada bordada, con el escaso margen de maniobra que existía en el río, la embarcación corría el riesgo de atravesarse y ser echada a pique por la fuerza de la corriente. Muchos habían sido los accidentes de cste tipo y la peor parte la llevaban siempre los pasajeros que, como solían ser de tierra adentro y no sabían nadar, se ahogaban sin remedio. Los marineros y patrones escapaban nadando y sin excesiva pena por la embarcación que perdían, pues siempre cobraban los crecidos pasajes por adelantado.

Mientras que los pasajeros y una buena parte de la carga usaba el transporte de los "barcos de la vez", las embarcaciones de altura abandonaban el puerto de las Muelas en Sevilla dirigidas por los prácticos del río. Los buques grandes iban descargados y los medianos a media

\footnotetext{
29 A un lector cuya lengua materna no sea el expañol, quizá haya que aclararle que "pedir la vez" es equivalente a solicitar turno o guardar cola.

30 Escalante de Mendoza, Juan. Itinerario de navegación..., pág. 29.

31 Gálvez. Ma Eugenia. "El Guadalquivir musulmán". En: El ro., pág. 27.
} 
carga. Comenzaba entonces el penoso paso de los bajos fluviales. Según López de Velasco, a menos de media legua de Sevilla, un bajo de arena denominado las Bandurrias era "...el peor que hay en todo el río, porque no llega a siete codos el agua en la pleamar, ni pasa de cuatro en la bajamar..."32. Para tener una idea ajustada de lo que significaba esa profundidad debe saberse que un codo era aproximadamente medio metro y que un galeón de mediano porte calaba fácilmente siete codos a plena carga ${ }^{33}$. Por todo ello Escalante establecía una serie de requisitos para pasar con seguridad los bajos del Guadalquivir:

1- Que el dueño de la embarcación se encuentre siempre a bordo, pues él, mejor que nadie, podría velar por la seguridad de su hacienda.

2- No dudar en alijar el buque ante la menor sospecha de que pudiera tocar en el fondo del río.

3- Llevar constantemente la sonda en la mano e iniciar el paso del bajo tan sólo unos momentos en que se alcanzase la pleamar (concretamente a los $5 / 6$ de la creciente).

4- Pasar bien de mañana para poder observar las marcas fijas de profundidad que marcaban cada bajo.

5- Si el cruce del bajo se realizaba por la tarde después de comer "...se tenga en cuenta que el piloto del río, si bebiera vino, que aquel día beba poco y muy aguado, porque como algunos de ellos andan siempre por la agua apetécenlo más de lo que convendría a su prontitud y memoria para la ejecución de su oficio..." 34 .

Con esas precauciones y contando con el viento y la corriente a favor, podían atravesarse los seis o siete lugares conflictivos que citan los autores de la época: los Pilares (del antiguo puente romano cercano a San Juan de Aznalfarache en las proximidades de Sevilla); el Valle (a dos leguas de San Juan de Aznalfarache); el Naranjal (a cuatro leguas de Sevilla); el

32 López de Velasco, Juan. Geografla..., pág. 35.

33 Archivo General de Indias, Indiferente General 2495. En la Real Cédula dada en San Lorenzo el Real el 12/X/1577, se fijaban las proporciones de los galeones que hacían de capitanas de las armadas de Indias, los cuales arquearían 550 toneladas y "...pescarían siete codos de agua...".

${ }^{34}$ Escalante de Mendoza, Juan. Itinerario de navegación..., págs. 27-28. 
Saucejo y, finalmente, las Horcadas, a ocho leguas de Sevilla y en la mitad del camino hacia la desembocadura. Allí las embarcaciones grandes se ponían a media carga y las medianas podían cargarse completamente. Al llegar a Sanlúcar se completaba la carga y se tomaba todo el pasaje.

El curioso personaje que en el libro de Escalante pregunta por las peculiaridades de la navegación por el Guadalquivir se asombraba de que en un río de aguas tranquilas pudieran perderse tantas naves, vidas y mercancías; la respuesta del experto piloto que se encarga de aclararle las dudas es la siguiente:

"Perderse una nao tan presto en los bajos de este rio....es por la mayor parte falta de cuidado y diligencia bastante, porque, como he dicho, un piloto de este rio, en viendo que toca en tierra la nao donde él va...viendo que corre peligro de perderse, sin decir cosa alguna, la deja y se mete en su barco y se va... y asi, comenzando a menguar la marea, inclinase la nao a caer de fuerza sobre uno de los costados y, en acostándose, se comienza a abrir y desgalibar y entrar agua dentro de ella, de manera que luego se anega y, anegada, se cubre de la misma agua encima de las cubiertas y, en acaeciendo esto, de esta suerte quedan perdidas las mercaderias... ${ }^{35}$.

Todo este cúmulo de problemas que reunía la navegación fluvial hasta Sevilla permiten comprender por qué, a pesar de lo que normalmente se ha afirmado, el puerto sevillano no gozó nunca de una completa exclusividad a la hora de organizar las expediciones a Indias. En los primeros años del descubrimiento de América, los puertos del litoral costero que va desde Cádiz a la desembocadura del Guadiana fueron origen y final de muchas expediciones. Luego, una vez que fue necesario organizar expediciones más complejas, las posibilidades demográficas, administrativas, financieras, y el deseo centralizador, impusieron a Sevilla como punto de origen $y$, sobre todo, de destino de las rutas atlánticas. Sin embargo, las dificultades de la vía fluvial que unía la metrópoli andaluza con el mar hicieron que, desde el comienzo, las embarcaciones que comenzaban a aparejarse en Sevilla terminasen de hacerlo en Sanlúcar, en Cádiz y hasta en Canarias, lugares que siempre tuvieron privilegios especiales para enviar sus barcos al Nuevo Mundo.

35 Ibidem. 
RESUMEN : En tanto puerto atlántico, Sevilla contó con las ventajas que le otorgaban la historia y la política, mientras que habían de serle fatales a mediano plazo los inconvenientes de la geografía. Una vida portuaria y urbana múltiple, hecha de esplendor y sinsabores. El río y sus trampas como componente ineludible del periplo indiano.

RESUME : Comme port atlantique, Séville était favorisée par l'histoire et la politique autant qu'elle était condamnée à moyen terme par les désavantages de la géographie. Une vie portuaire et urbaine multiple, faite de splendeurs et de désagréments. Le fleuve et ses pièges comme composante inéluctable du voyage américain. 